\title{
Carbon dioxide as the main hazard in the design of personal ventilation systems
}

\author{
Igor Zvenigorodsky ${ }^{1}$, Dmitry Lobanov ${ }^{2, *}$, Alexander Mershchiyev ${ }^{2}$ and Roman Sheps ${ }^{2}$ \\ ${ }^{1}$ Military Training and Scientific Center of the Air Force "Air Force Academy named after Professor \\ N. E. Zhukovsky and Yu. A. Gagarin", Starikh Bolshevikov St., 54«A», Voronezh, 394064, Russia \\ ${ }^{2}$ Voronezh State Technical University, 20-letiya Oktyabrya St., 84, Voronezh, 394006, Russia
}

\begin{abstract}
Mental work, used everywhere at present, is quite diverse and is characterized by various degrees of responsibility, monotony, attention, and the level of emotional stress. To provide comfortable living conditions for a person in a permanent workplace, it is also necessary to organize air conditioning systems. The most promising for this activity are personal ventilation systems, which provide a high-quality air environment in the area of human breathing while reducing capital and operating costs in comparison with traditional (mixing, displacement ventilation). However, when designing personal ventilation systems, one should not focus on the "average reference man", but take into account the individual characteristics of the employee (age, gender, etc.) performing a specific type of mental activity. In order to clarify the actual value of carbon dioxide (with a certain degree of error) emitted by a person in a certain mental work, we perform a series of experiments. The authors conducted a significant amount of full-scale experimental investigations, the result of which is the confirmation of nature and dynamics of carbon dioxide's changes in the room in the absence (inactivity) of ventilation systems (linear dependence), as well as the refinement of the amount of carbon dioxide emitted in a particular type of mental activity. It should be noted that this work is the beginning of large-scale scientific research designed to collect and systematize data on emissions of harmful substances from people engaged in various types of mental activity.
\end{abstract}

\section{Introduction}

Nowadays when designing ventilation systems of buildings, a significant amount of work falls on the development of documentation for offices. The main source of harmful substances input is a person who releases heat, moisture and gaseous substances $[1,2]$. When calculating, designing and constructing the ventilation systems, it is necessary to take into account the quantity and nature of the distribution of these hazards in the room. These rooms belong to the second category and standardized parameters of the internal microclimate are provided for them: temperature, humidity, mobility. In modern world, more and more attention is paid to the quality of the indoor air environment, the main indicator of which is carbon dioxide (CO2) [3].

\footnotetext{
*Corresponding author: LDV-36@mail.ru
} 
The aim of this work is to determine experimentally the amount of carbon dioxide entering the room from a person engaged in mental work. Data on the amount of carbon dioxide emitted by an adult, depending on the conditions, are summarized in table 1.

Table 1. The amount of carbon dioxide emitted by an adult, depending on the conditions.

\begin{tabular}{|l|c|c|c|c|}
\hline \multirow{2}{*}{ Harmful conditions } & \multicolumn{5}{c|}{ The amount of carbon dioxide emitted by an adult, I } \\
/ h
\end{tabular}

* - no data

In our opinion, mental work as well as physical work, is different (secretary, writer, air traffic controller, etc.) and is characterized by an unequal level of emotional stress. Therefore, when calculating the amount of harmfulness, it is necessary to take into account the type of mental activity, and when designing systems for providing comfortable microclimate parameters, one should not focus on the "average reference man" [4], but have regard to its individual characteristics (age, gender, etc.). In order to clarify the actually emitted carbon dioxide (with a certain degree of error) by a person in a particular mental work, we will perform a series of experiments.

\section{Experimental}

Let at the initial moment of time the concentration of carbon dioxide in the room air is $\mathrm{C}_{0}^{\mathrm{co}}$, $\mathrm{mg} / \mathrm{m} 3$. If at this moment the source of emission of harmful substances with an intensity of $\mathrm{M}_{\mathrm{CO} 2}, \mathrm{mg} / \mathrm{h}$ begins to operate in the room, then the equation of the balance of harmful substances at any time has the form [4]:

$$
\mathrm{M}_{\mathrm{CO} 2} \mathrm{~d} \tau-\mathrm{V}_{\text {room }} \mathrm{dC}=0,
$$

where $V_{\text {room }}$ is the volume of room, $\mathrm{m} 3$.

The equation is valid under the assumption that harmful substances are distributed evenly throughout the entire volume of the room, and the desired concentration of the harmful substance $\mathrm{C}^{\mathrm{co} 2}, \mathrm{mg} / \mathrm{m} 3$ is an average volume value.

Integrating the equation (1) from 0 to $\tau$ (arbitrary time) and solving the current concentration of $\mathrm{C}^{\mathrm{co} 2}$, we obtain:

$$
\mathrm{C}^{\mathrm{co2}}=\mathrm{C}_{0}^{\mathrm{co2}}+\frac{\mathrm{M}_{\mathrm{CO2}}}{\mathrm{V}_{\text {room }}} \tau
$$

Thus, the amount of carbon dioxide $\mathrm{M}_{\mathrm{CO} 2}, \mathrm{mg} / \mathrm{h}$ entering the room when performing mental work, is determined by the formula:

$$
\mathrm{M}_{\mathrm{CO} 2}=\frac{\left(\mathrm{C}^{\mathrm{co} 2}-\mathrm{C}_{0}^{\mathrm{co} 2}\right) \mathrm{V}_{\text {room }}}{\tau}
$$

In this case, the main source of harmful substance emission is a person, therefore it is necessary to take into account his physiology [5] and features when performing various types of activities [6].

According to [7], the minute expiratory volume of respiration, i.e. the volume of air inhaled (or exhaled) for 1 minute $\mathrm{Ve}, 1$ / $\mathrm{min}$, is equal to: 


$$
\mathrm{Ve}=\mathrm{Vt} \times \mathrm{f}
$$

where Vt - expiratory tidal volume, 1 ; f - respiratory rate, 1 / min

The frequency of adult respiratory rate at rest can undergo significant fluctuations from 10 to 18 in a minute $[7,8]$ (in average of $14 / \mathrm{min}$ ); due to individual indicators of external respiration, the normal respiratory rate varies from 16 to 25 per minute [8].

From equation (4) it follows that the minute volume of breathing for adult (with a tidal volume of $0.5 \mathrm{l})$ is from $5 \mathrm{l} / \mathrm{min}(300 \mathrm{l} / \mathrm{h})$ to $12.5 \mathrm{l} / \mathrm{min}(750 \mathrm{l} / \mathrm{h})$ of air.

According to [8], the minute volume of breathing during mental work, including the mental and emotional components, (in the absence of prolonged emotional stress associated with the reactions of the vegetative nervous system and expressed by the mood of a person in the form of joy, anger, sorrow) will be compared with a state of repose.

During physical activity, in accordance with an increase in oxygen demand, the minute volume of breathing also increases, reaching $1201 / \mathrm{min}$ (trained people) under conditions of maximum load $[8,9]$; an untrained person with maximum muscle work has the minute volume of breathing which does not exceed $801 / \mathrm{min}$ [9].

The composition of respiratory gases inhaled and exhaled by a person in a calm state (at sea level) is presented in table 2.

Table 2. Composition of inhaled and exhaled air under normal conditions.

\begin{tabular}{|l|c|c|c|}
\hline \multirow{2}{*}{\multicolumn{1}{|c|}{ Air }} & \multicolumn{3}{|c|}{ Gas content, $\%$} \\
\cline { 2 - 4 } & $\mathbf{O}_{\mathbf{2}}$ & $\mathbf{C O}_{\mathbf{2}}$ & $\mathbf{N}_{\mathbf{2}}$ \\
\hline Inhaled & 20.94 & 0.03 & 79.03 \\
\hline Exhaled & 16.30 & 4.00 & 79.70 \\
\hline Alveolar & 14.20 & 5.20 & 80.60 \\
\hline
\end{tabular}

Due to the fact, that the concentration of carbon dioxide in the exhaled air (table 1) is approximately $4 \%(3.4 \ldots 4.7 \%)$, the total amount of carbon dioxide exhaled will be from $121 / \mathrm{h}$ (respiratory rate is $10 / \mathrm{min}$ ) to $301 /$ hour (respiratory rate is $25 / \mathrm{min}$ ), see Figure 1 .

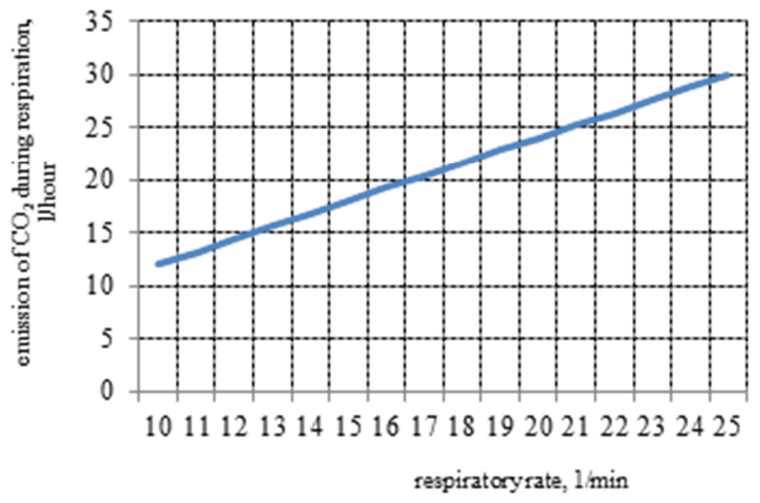

Fig. 1. Emission during respiration of $\mathrm{CO}_{2}$ at different frequencies of respiratory movements.

We performed an experimental determination of the amount of carbon dioxide entering the room from a person engaged in mental work. Measurements of changes of $\mathrm{CO} 2$ concentration were carried out in a room, the geometric characteristics of which are shown in Figure 2. 


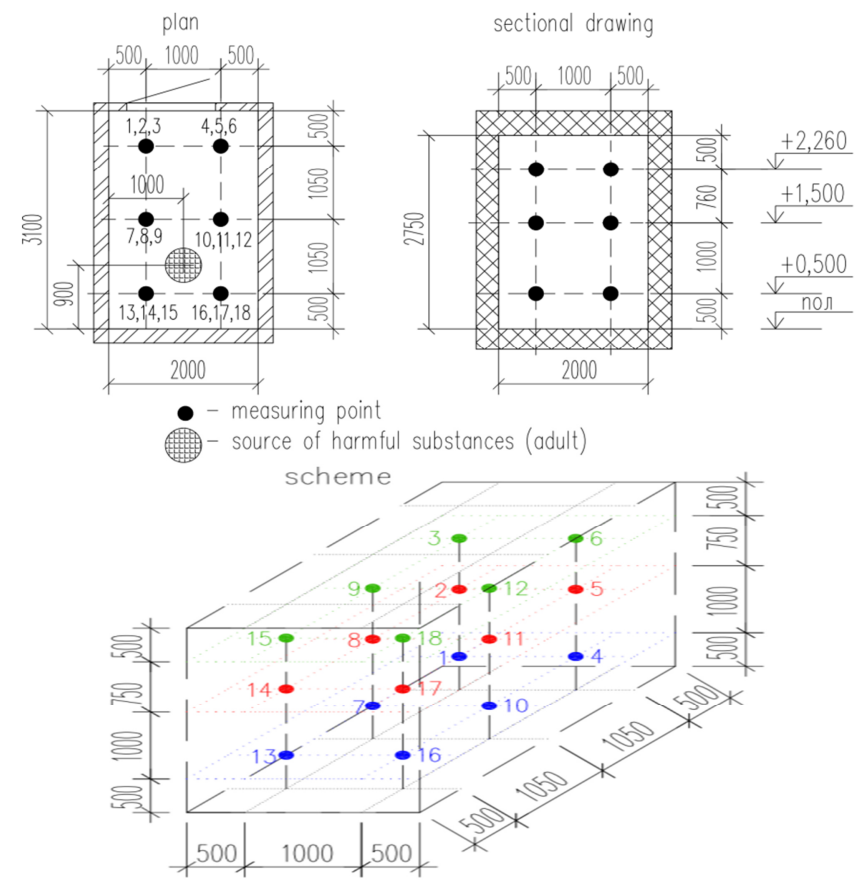

Fig. 2. The geometric characteristics of the room and measuring points.

To measure the change of carbon dioxide concentration, the PCE-GA 70 combined indoor air quality assessment instrument was used (Figure 3).

Appearance of the device

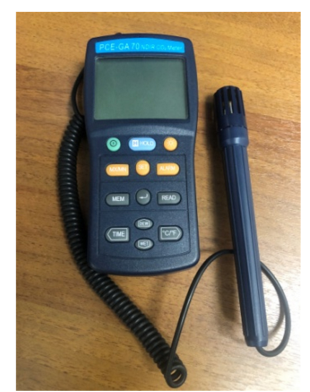

The main technical characteristics

Concentration measurement range of $\mathrm{CO}_{2}-0 \ldots 6000$ ppm; Concentration accuracy of $\mathrm{CO}_{2}- \pm 3 \% \pm 50$

ppm; Concentration measurement resolution of $\mathrm{CO}_{2}-$ $1 \mathrm{ppm}$

Temperature measurement range $-20^{\circ} \mathrm{C} \ldots+60^{\circ} \mathrm{C}$;

Temperature accuracy $\pm 0,5^{\circ} \mathrm{C}$; Temperature measurement resolution $-0,1^{\circ} \mathrm{C}$

Range of measurements of relative air humidity $10 \% \ldots 95 \%$; Relative humidity measurement accuracy $\pm 3 \%$; Relative humidity measurement resolution $0,1 \%$.

Fig. 3. Appearance and technical characteristics of the PCE-GA 70 combined indoor air quality assessment instrument.

Work sequence:

Taking into account the geometric characteristics of the room, it was broken down with the placing of measuring points in plan and in height (Figure 2). There is one workplace in the room (Figure 4). 

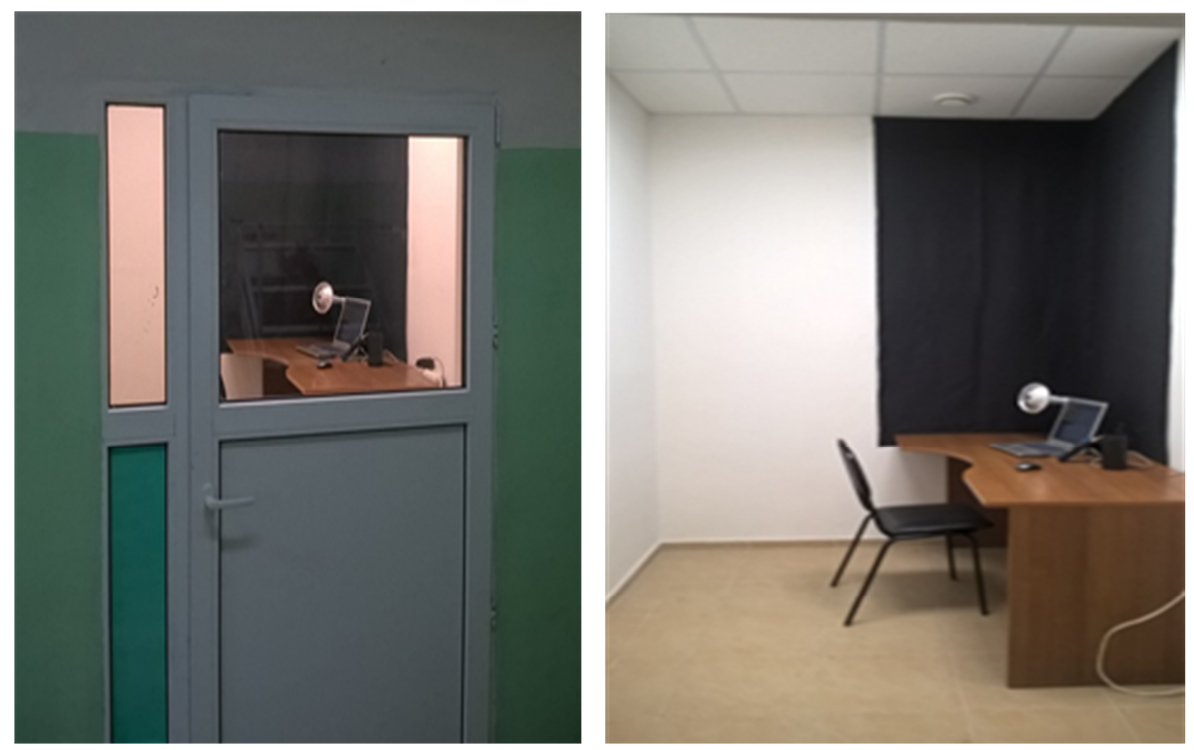

Fig. 4. The room of mental work with the location of one permanent workplace.

There is a person (male, 30 years old) in the room (Figure 4), engaged in mental work at a laptop (creative work, design). Measurements were carried out continuously for an hour, for each of the points indicated in Figure 2: a device, which fixes and stores in automatic mode on a PC with an interval of 60 seconds of the value of carbon dioxide concentration was installed (Figure 3). These values, issued in tabular form, were subsequently used for graphing in Excel. After an hour, the device was moved to another calculated point and the initial concentration of carbon dioxide of $450 \mathrm{ppm}$ was achieved by airing or turning on ventilation. During the experiment, there were no internal and external disturbing influences capable to change the mobility of air in the room or affect the amount of harmful substances emitted. The experiments were carried out for two days (nine points per day), ceteris paribus.

\section{Evaluation}

As a result, we obtained curves of distribution in space and changes in time of carbon dioxide concentration values (Figure 5). 

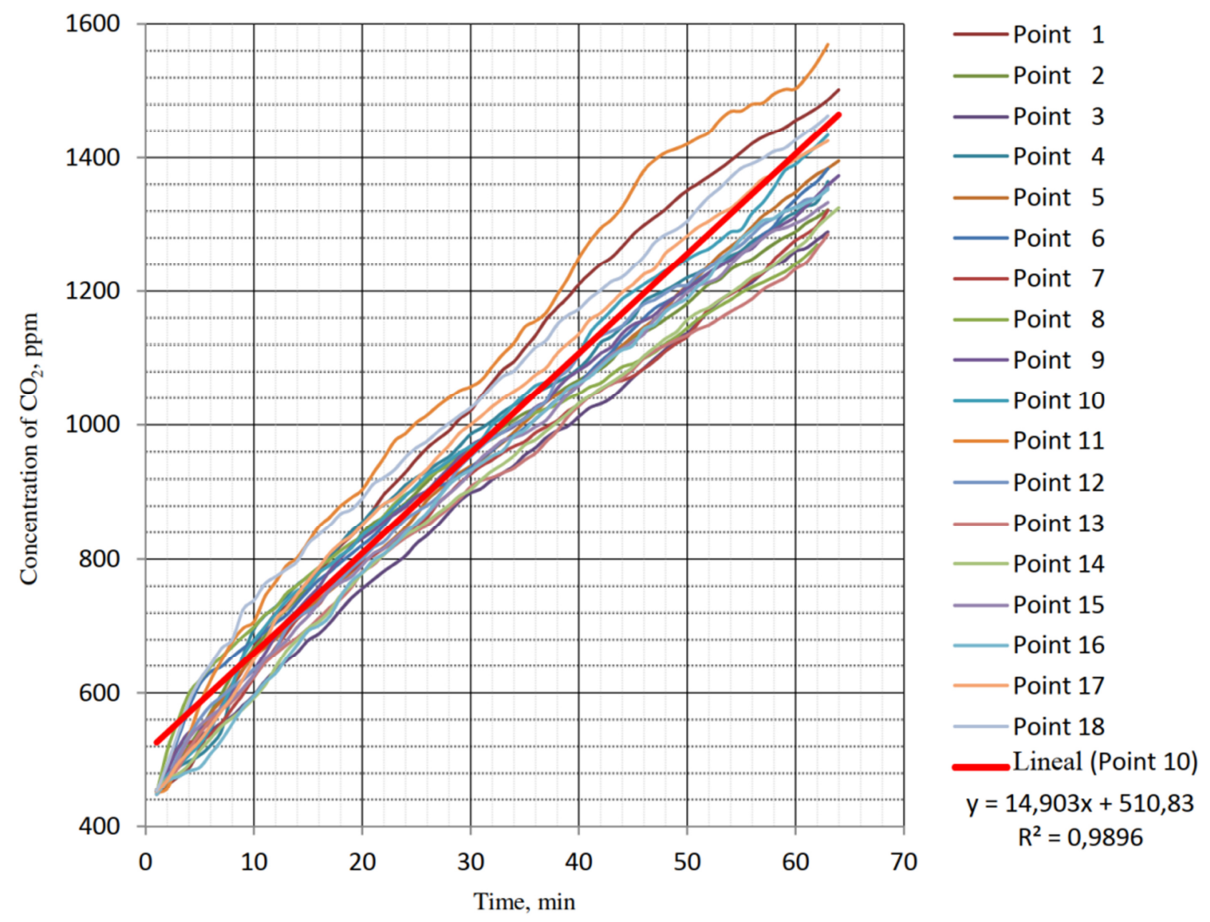

Fig. 5. Distribution and excursion in the concentration of carbon dioxide.

Based on the obtained experimental data, we establish the amount of carbon dioxide from a person during an hour for points that are different in plan and volume of the room according to Fig. 2 (table 3).

Table 3. The amount of $\mathrm{CO}_{2}$ from a person for different points in the room.

\begin{tabular}{|c|c|c|c|c|c|c|c|c|}
\hline \multirow{2}{*}{$\begin{array}{c}\text { Numbe } \\
\mathbf{r} \text { of } \\
\text { point }\end{array}$} & \multicolumn{3}{|c|}{ Value of $\mathrm{CO}_{2} \cdot \mathrm{ppm}$} & \multirow{2}{*}{$\begin{array}{l}\Delta \mathrm{CO}_{2} . \\
\mathrm{mg} / \mathrm{m}^{3}\end{array}$} & \multirow{2}{*}{$\begin{array}{c}\text { G. } \\
\text { mg/h }\end{array}$} & \multirow[t]{2}{*}{ G. kg/h } & \multirow[t]{2}{*}{ G. $\mathrm{m}^{3} / \mathrm{h}$} & \multirow[t]{2}{*}{ G. $\mathbf{l} / \mathbf{h}$} \\
\hline & initial & final & $\Delta \mathrm{CO}_{2}$ & & & & & \\
\hline 1 & 447 & 1502 & 1055 & 1929.95 & 32906 & 0.0329 & 0.01665 & 16.646 \\
\hline 2 & 449 & 1322 & 873 & 1597.01 & 27229 & 0.0272 & 0.01377 & 13.774 \\
\hline 3 & 452 & 1289 & 837 & 1531.15 & 26106 & 0.0261 & 0.01321 & 13.206 \\
\hline 4 & 454 & 1364 & 910 & 1664.69 & 28383 & 0.0284 & 0.01436 & 14.358 \\
\hline 5 & 455 & 1395 & 940 & 1719.57 & 29319 & 0.0293 & 0.01483 & 14.831 \\
\hline 6 & 452 & 1383 & 931 & 1703.11 & 29038 & 0.0290 & 0.01469 & 14.689 \\
\hline 7 & 452 & 1321 & 869 & 1589.69 & 27104 & 0.0271 & 0.01371 & 13.711 \\
\hline 8 & 449 & 1270 & 821 & 1501.88 & 25607 & 0.0256 & 0.01295 & 12.954 \\
\hline 9 & 451 & 1373 & 922 & 1686.65 & 28757 & 0.0288 & 0.01455 & 14.547 \\
\hline 10 & 453 & 1434 & 981 & 1794.58 & 30598 & 0.0 & 0.01548 & 15.478 \\
\hline 11 & 450 & 1569 & 1119 & 2047.02 & 34902 & 0.0349 & 0.01766 & 17.656 \\
\hline 12 & 447 & 1355 & 908 & 1661.03 & 28321 & 0.0283 & 0.01433 & 14.327 \\
\hline 13 & 451 & 1285 & 834 & 1525.66 & 26013 & 0.0260 & 0.01316 & 13.159 \\
\hline 14 & 452 & 1325 & 873 & 1597.01 & 27229 & 0.0272 & 0.01377 & 13.774 \\
\hline 15 & 448 & 1333 & 885 & 1618.96 & 27603 & 0.0276 & 0.01396 & 13.964 \\
\hline 16 & 447 & 1352 & 905 & 1655.55 & 28227 & 0.0282 & 0.01428 & 14.279 \\
\hline 17 & 452 & 1425 & 973 & 1779.94 & 30348 & 0.0303 & 0.01535 & 15.352 \\
\hline 18 & 453 & 1463 & 1010 & 1847.63 & 31502 & 0.0315 & 0.01594 & 15.936 \\
\hline mean & 450.78 & 1375.556 & 924.8 & 1691.73 & 28844 & 0.02884 & 0.01459 & 14.591 \\
\hline
\end{tabular}


value

Table 3 shows that the mean value of the final concentration of carbon dioxide is 1375.6 ppm and corresponds to the value at point 9 of the room (see Fig. 2). It can be seen from the obtained experimental data (see Fig. 5) that the change in carbon dioxide concentration during an hour is described by a linear function with a high degree of reliability of the approximation $\mathrm{R} 2=0.9896$ :

$$
\mathrm{y}=14,903 \times \mathrm{X}+510,83 .
$$

Compare the resulting equation (5) with (2). These are equations of right lines describing changes in the concentration of a harmful substance in a room in the absence of ventilation, obtained theoretically [6] and experimentally. We solve equation (3), substituting the required values obtained as a result of the experiment:

$$
\begin{gathered}
\mathrm{C}_{0}^{\mathrm{CO} 2}=451 \mathrm{ppm}=825 \frac{\mathrm{mg}}{\mathrm{m} 3} \\
\mathrm{C}^{\mathrm{CO} 2}=1373 \mathrm{ppm}=2512 \mathrm{mg} / \mathrm{m} 3 \\
\mathrm{~V}_{\text {pom }}=17,05 \mathrm{~m} 3 \\
\mathrm{M}_{\mathrm{CO} 2}=\frac{(2512-825) * 17,05}{1}=28763 \mathrm{mg} / \mathrm{h}(14,55 \mathrm{l} / \mathrm{h})
\end{gathered}
$$

So, we determined that the amount of carbon dioxide into the room from a person engaged in mental work is $14.61 / \mathrm{h}$. Compared the resulting number with table 1 (for mental work), it is clear that the number 14.6 is less than the number 23 by $36.52 \%$.

\section{Conclusions}

The linear dependence (5) of the change in the concentration of the harmful substance (CO2), which is confirmed by the formula (2) [10], has been experimentally established.

The amount of $\mathrm{CO} 2$ input into the room from a person engaged in mental work was obtained $(14.61 / \mathrm{h})$. This value is included in the range defined by Figure 1, made according to the data of [11].

Figure 1 shows that the amount of $\mathrm{CO}_{2}$ entering the room from a person is in a wide range; it depends on the individual characteristics and type of work [12]. However, the average value is $21 \mathrm{l} / \mathrm{h}$, which corresponds to the data in table 1 .

It should be noted that when designing general exchange of ventilation systems in public buildings, data oriented to a "average reference" man [12-14] specified in should be used: the amount of carbon dioxide intake is $231 / \mathrm{h}$.

When designing personal ventilation systems in the rooms of mental work, it is necessary to know the data of the end user in order to clarify the amount of incoming hazards and determine the estimated air exchange.

Personal ventilation system is a promising direction for creating comfortable parameters of the air environment at permanent workplace of the rooms of mental work.

Physiologically intellectual (mental) activity is characterized by a brain tension based on the concentration of attention on a limited circle of phenomena or objects. Therefore, the distinguishing features of mental work are considered to be a high strain of the central nervous system and sensory organs with limited physical activity. The body's response to mental work changes significantly if it occurs against the background of emotional experiences. Troubles and excitement, anger and impatience, tension in a compressed time frame affect the circulatory system. Mental work is quite diverse: scientist, accountant, 
student, manager, air traffic controller, secretary, etc. Each profession is characterized by a different degree of responsibility, monotony, attention, level of emotional stress. Mental work is performed by people of different ages, gender, nationalities, having different physiological characteristics.

All of the above affects the amount of carbon dioxide emitted by a person during the performance of a particular mental activity. In our opinion, it is necessary to conduct numerous experimental studies aimed at studying the amount of carbon dioxide emitted by people, depending on the nature of mental work, as well as taking into account their physiological and other characteristics.

To conduct further scientific research the authors at the Department of Housing and Communal Services of the Federal state budget educational institution of Voronezh state technical university have created in one of the laboratories the conditions for implementing measures to collect and systematize data on the emissions of harmful substances from people engaged in various mental work.

\section{References}

1. V. Pukhkal, N. Vatin, V. Murgul, Applied Mechanics and Materials 633-634, 10771081 (2014) DOI:10.4028/www.scientific.net/AMM.633-634.1077

2. G. Liu, Y. Huang, J. Wang, Energy 18915, 116323 (2019) DOI: https://doi.org/10.1016/j.energy.2019.116323

3. V. Murgul, D. Vuksanovic, N. Vatin, V. Pukhkal, Applied Mechanics and Materials 680, 524-528 (2014) DOI:10.4028/www.scientific.net/AMM.680.524

4. A. Meiss, J. Feijó-Muñoz, M.A. García-Fuentes, Energy and Buildings 67, 88-96 (2013) DOI: https://doi.org/10.1016/j.enbuild.2013.08.016

5. T.C. Callari, N. McDonald, B. Kirwan, K. Cartmale, Safety Science 120, 838-849 (2019) DOI: https://doi.org/10.1016/j.ssci.2019.08.027

6. V.G. Gagarin, K.I. Lushin, V.V. Kozlov, A.Y. Neklyudov, Procedia Engineering 1462016, 103-111 (2016) DOI: https://doi.org/10.1016/j.proeng.2016.06.359

7. T. Lehouillier, F. Soumis, J. Omer, C. Allignol, Computers \& Industrial Engineering 99, 269-279 (2016) DOI: https://doi.org/10.1016/j.cie.2016.07.025

8. B. Yang, A.K. Melikov, A. Kabanshi, et al., Energy and Buildings 2021, 109359 (2019) DOI: https://doi.org/10.1016/j.enbuild.2019.109359

9. A. Abd Aziz, D. Sumiyoshi, Y. Akashi, MATEC Web of Conferences 225, 04016 (2018) DOI: https://doi.org/10.1051/matecconf/201822504016

10. K.F. Fong, C.K. Lee, Z. Lin, Renewable Energy 131, 413-421 (2019) DOI: https://doi.org/10.1016/j.renene.2018.07.065

11. A. Mikuckas, D. Ciuzas, T. Prasauskas et al., Applied Mathematical Modelling 42, 290-299 (2017) DOI: https://doi.org/10.1016/j.apm.2016.10.030

12. S.A. Gómez, A. Goron, A. Groza, I.A. Letia, Expert Systems with Applications 44, 367-385 (2016) DOI: https://doi.org/10.1016/j.eswa.2015.09.027

13. H.J. Rickenbacker, W.O. Collinge, V. Hasik et al., Sustainable Cities and Society 52, 101831 (2020) DOI: https://doi.org/10.1016/j.scs.2019.101831

14. T. Lehouillier, F. Soumis, J. Omer, C. Allignol, Computers \& Industrial Engineering 99, 269-279 (2016) DOI: https://doi.org/10.1016/j.cie.2016.07.025 